DigiTALCOMMONS @WAYNESTATE-
Michigan Journal of Counseling: Research, Theory and Practice

Volume 39 | Issue 1

Article 3

$1-1-2012$

\title{
Second Life: Implications for Counselor Education
}

Tomeka W. McGhee

University of Alabama at Birmingham, drtwmcghee@gmail.com

Maranda Brown

Troy University

Felicia Pressley

Auburn University

Brandon Browning

Auburn University

Chippewa Thomas

Auburn University

Follow this and additional works at: https://digitalcommons.wayne.edu/mijoc

\section{Recommended Citation}

McGhee, T. W., Brown, M., Pressley, F., Browning, B., \& Thomas, C. (2012). Second Life: Implications for Counselor Education, Michigan Journal of Counseling, 39(1), 19-30. doi:10.22237/mijoc/1325376120

This Article is brought to you for free and open access by the Open Access Journals at DigitalCommons@WayneState. It has been accepted for inclusion in Michigan Journal of Counseling: Research, Theory and Practice by an authorized editor of DigitalCommons@WayneState. 


\section{Second Life: Implications for Counselor Education}

Tomeka W. McGhee

University of Alabama at Birmingham

Maranda Brown
Troy University

Felicia Pressley, Brandon Browning, and Chippewa Thomas Auburn University

Abstract

Virtual world technology is becoming an invaluable tool. Increasingly, institutions of higher learning are using virtual world technology to facilitate education and communication. Second Life (SL) is a three dimension virtual world which demonstrated usefulness for the counseling profession. This article seeks to elucidate the potential of SL for programs that facilitate counselor education, training and preparation. Implications for counselor education and future research are discussed.

Virtual world technology offers an environment for web-based learning, e-business, web play, and course management (i.e. vehicle for class discussions) (Childress \& Braswell, 2006; Gaimster, 2007). Virtual world technology has also been commonly associated with video games like SIMS, Everquest and for social community web pages like Twitter, Pinterest, Facebook and MySpace (Skiba, 2007). In addition, virtual world technology offers many opportunities for students in higher education to expand their knowledge beyond the classroom. Because virtual world software offers a continuous, multiplayer, 3-D environment, it provides students opportunities for research and experiments (Jencius, 2009; Skiba, 2007). Virtual worlds are simulated environments in which users interact as graphic avatars. Second Life (SL) is one of the most currently recognized public virtual worlds (Jencius, 2009). The purpose of this article is to illustrate the potential of SL for programs that facilitate counselor education, training and preparation.

Tomeka W. McGhee is now at the Department of Human Studies, University of Alabama at Birmingham, Alabama. Maranda Brown is at the Counseling and Psychology Department, Troy University, Montgomery, Alabama. Felicia Pressley is a part of Special Education, Rehabilitation and Counseling, Auburn University, Alabama. Brandon Browning is at the Academic Counseling and Advising Center, Auburn University, Alabama. Chippewa Thomas is a part of the Office of Vice President for University Outreach/Faculty Engagement, Auburn University, Alabama. Correspondence concerning this article should be addressed to Tomeka W. McGhee, Department of Human Studies, University of Alabama at Birmingham, $15303^{\text {rd }}$ Avenue South, Room 207, Birmingham, Alabama 35294-1250. Email: drtwmcghee@gmail.com. 
What is SL actually? SL is web-based software developed by Linden Research, Inc. (Linden Lab), a company located in California. SL was launched in 2003 (Bell, Pope, \& Peters, 2008; Descy, 2008; Geck, 2008; Jencius, 2009; Skiba, 2007). SL was created for Massive Multiplayer online gaming (MMOG). $\mathrm{SL}$ is a huge online computer simulated environment that allows a person to enter as a resident, move around, and interact with other residents known as avatars. The three dimensional virtual world is designed, built and owned by residents (Bell, Pope, \& Peters, 2008; Jencius, 2009; Kelton, 2008; Skiba, 2007). Avatars are computerized three dimensional characters that interact within SL (Liao, 2008). Thus, a resident can develop a personality with real life characteristics in SL (Bessiere, Fleming, Seay, \& Kiesler, 2007; Descy, 2008).

Second Life can also be used for training within the environment (Trotter, 2008). SL is becoming a widely used tool for communication and for gaining (real world) simulated virtual experience (Goral, 2008; Guest, 2007). Virtual world technology such as SL serves a global audience offering many languages without communication boundaries (Bell, Pope, \& Peters, 2008). Although English is the official language of SL, there are areas for groups who speak Chinese, French, German, and Japanese. SL has been used recently as an educational tool, as a virtual library, for psychology and medical (nursing) education, and professional recruitment (Descy, 2008; Olsen, 2000).

Second Life provides opportunities for students in higher education to expand their knowledge beyond the classroom. Because of the increase in use of computer technology over the past years in higher education, the number of distance education offerings, online classes and virtual campuses is growing (Foster, 2007; Goral, 2008; Harasim, 2000; Robbins-Bell, 2008; Trotter, 2008). As early as 2005 , courses on many college campuses have been incorporating SL (Childress \& Braswell, 2006). Currently, SL has a program for educators to use in their classes; designed specifically for higher education (Childress \& Braswell, 2006). Over thirteen million members, including colleges and universities (e.g., Harvard, Stanford, Cambridge, Princeton, Pepperdine, Drexel, Ball State, and Stanford) navigate through and inhabit the SL community. Recently, as many as 250 universities and colleges have designed virtual campuses within Second Life (Goral, 2008). Likewise, many universities (e.g., Pepperdine and Princeton) are working within the virtual world of SL to promote technological education and are on the Second Life education listserve known as SLED (Descy, 2008). According to Trotter (2008), the higher education community is thriving in the SL virtual world. Many educational institutions are creating campuses in SL to enhance the students' learning experiences (Bugeja, 2008; Descy, 2008; Foster, 2007). Furthermore, virtual worlds are gaining notoriety as a pedagogical stage (Jencius, 2009).

For the profession of counseling, SL has been used in many capacities (e.g., to facilitate life coaching, peer support, support groups and advocacy) (Jencius, 2009; Young, 2007). Further, it has experienced a range of success using various virtual types (Jencius, 2009). Concerns surrounding various issues (e.g., confidentiality not being guaranteed, shallow encounters, obtaining informed consent, verifying client and counselor identity authenticity, and consumer protection and enforcing state licensure laws) are still being addressed for virtual counseling practice. Contextual issues continue to include the appeal 
of internet counseling, efficiency, employment compatibility, privacy, textreliance attraction, the nature of the psychological disorder, cost, and risk (Patrick, 2007; Yee, Bailenson, Urbanek, Chang, \& Merget, 2007).

Practice implications continue to influence the future of online counseling in the form of the development of standards of competency, certification models, and the proliferation of research (Patrick, 2007). The benefits and challenges of a virtual technology medium, like SL, are not isolated to counseling and clinical practice of psychotherapy. Just as SL provides counselors-inpractice a means of interacting with clients and delivering treatment, it has the potential to expand learning and generate new learning experiences for counselors-in-training. Therefore, Second Life can be used clinically in training and skills development for students who are in need of practice in the virtual world in preparation for real world experiences. As an increasingly popular tool in education and counseling, programs that prepare, train and educate future counselors have begun to explore SL as an instructional technology for student training. Finally, this article will address the potential uses for Counselor Education programs in Second Life.

\section{Counselor Education and SL}

As counselor education programs equip individuals for working in a multiplicity of environments, it is essential that the integration of virtual worlds, such as Second Life (SL), be explored. Users of SL rather quickly find that it has no geographic boundaries and serves global users, making it universally accessible and useful. The creators of SL purport education as a core function (Trotter, 2008) and even provide discounted fees to educators who use it. Counselor education programs potential for benefit in SL is limited only by their inability to charter new technological territory. Various counseling professionals are currently utilizing SL to host meetings/activities/events, to create simulated experiences, to facilitate campus program recruitment, host virtual campus tours, and for marketing (i.e. center for Counselor Educators in SL [CESL] sl.counseloreducation.org) (Jencius, 2009). Once a presence is established, programs can utilize their space for communication, to mirror and expand the traditional classroom, and for collaboration (Lebel, Olshtain, \& Weiss, 2005). The potential within the SL virtual world is vast. Consider the following potentialities.

\section{Counselor Education Programming}

The process of applying to graduate programs in counselor education can involve certain steps. Applicants may find this process challenging when programs are a great distance away from their locality. Program websites that contain electronic forms, email contact capability, and other tools (i.e. faculty pictures, and program handbooks) make the application process less challenging. The program marketability and capacity for recruitment thereby has the potential to draw in a great number of potential students beyond that of the local population. For this purpose counselor training programs could develop virtual campuses in SL. The low cost of a virtual world in SL could also make it possible for counselor education programs to market their programs to students that might only be reached through more costly advertising methods. As a communi- 
cation tool, virtual campuses could be utilized for program recruitment within the SL community by establishing an island for the department where interactive tours could take place. Ohio University has found that the creation of their virtual campus has greatly benefited them from a marketing perspective (Goral, 2008). These initiatives can be extremely beneficial to colleges or universities who may not have the national visibility they desire. Berger (2008) illustrates this approach by noting that the Office of Undergraduate Admissions at Case Western Reserve has started inviting admitted and prospective students to a virtual campus that includes various representatives of the school and surrounding community.

Conducting initial screening and selection interviews could also be accomplished in SL. Interviews for admission consideration can be done in SL before a more formal face-to-face interview is considered and conducted. Screening interviews in SL could cut down the cost of applicants having to travel for an initial interview. Hewlett-Packard recently participated in a job fair held within SL along with Verizon and Microsoft and noted the cost savings advantage of eliminating travel cost (Athavaley, 2007). Hypergrid Business also notes that in today's economy, having a budget to cover travel expenses is not plausible so virtual interviews are often used for recruitment and hiring (Korolov, 2010). Screening interviews in SL have the potential to allow admission committees to make screening decisions before offering face to face interviews.

Screening interviews in SL could also provide more applicants with more information upon which to make their decisions about entering a counselor training program. Inherently limitations exist, but this approach has the potential to enhance counselor education programming. Expanding upon this concept, prospective students could dialog with current counselor education students in the process applying to a program. In addition to potential recruitment opportunities, Gaimster (2007) points to the fact that virtual worlds can be used as powerful tools to develop creative approaches to learning.

\section{Learning and Skill Development}

Constructivist learning theory is highlighted within SL capability. Constructivist learning is fostered when students are placed in contact with others, in an immersive environment that challenges them to create, construct and figure out approaches and strategies for themselves (Reicherzer, Dixon-Saxon, \& Trippany, 2009; Skiba, 2007). As academia begins to welcome net generation learners, it is becoming increasingly more important to enhance instruction with technology to increase sustainability of the learner's engagement. SL can be an important aspect in the continuum of learning methods available to the instructor (Cheal, 2007). The active learning that is fostered within SL challenges more traditional approaches to teaching (e.g., lecture method), which can result in a passive learning audience (Cheal, 2007). Because the SL environment is more relaxed it can also foster a greater rapport among students and the instructor. The environment can allow (for example) an introverted personality to become more functional for engaging easily in communication as a course participant (Markham, 1998). Individual students may find it easier to express themselves because of the capacity to utilize an avatar to represent them (Bessiere, Flem- 
ing, Seay, \& Kiesler, 2007).

Berger (2008) found that some students felt the online environment freed them from debilitating shyness and allowed them to express themselves more comfortably than they could in a traditional classroom. Positive social and academic interactions have the potential to impact the student's confidence and academic performance (e.g., levels of emotional dependency students have on their instructors) (Gaimster, 2007). Furthermore, Jarmon, Traphagan, and Mayrath (2008) noted that the diverse interaction of students within the SL media are more likely to experience positive contact and a shared understanding due to the elimination of geographical barriers and reduction in social anxiety which promotes ease of disclosure. Educators can utilize the immersive elements of virtual worlds to create dynamic interactive learning environments, but only if they adopt additional pedagogies. Simply holding a lecture in SL is not going to transform the student experience. Although getting students involved in an authentic learning situation that is emotionally engaging might allow students to learn cooperatively and deepen questioning and reflection (Gaimster, 2007; Reicherzer, Dixon-Saxon, \& Trippany, 2009). Engaging in this environment will require educating users about norms, structure, and boundaries in order to help users build confidence and feel comfortable. Students' technical skills can also be a factor in how quickly or to what degree students adapt and benefit from interactions in a virtual world (Petrakou, 2010). Additional learning based examples are also discussed in the literature.

When a traditional learning environment is supplemented with a more experiential learning environment similar to what SL provides, it offers students a unique and flexible environment for distance learning (Skiba, 2007); thus contributing to student engagement. The possibilities for facilitating learning with SL extend beyond your typical hybrid course because of its three dimensional capabilities. Kinesthetic learners may be some of the greatest benefactors of these teaching methods. Because of the ability to use simulation, experiential learning is enhanced, allowing individuals to practice skills and try on new ones (Skiba, 2007). Kinesthetic learners are often isolated when traditional teaching methods are solely employed. Having the ability to simulate learning opportunities provides for experiential exploration of concepts that learners have been hard pressed to have.

One such example noted by Graham (2007) of the potential that lies within SL has been demonstrated by the University of California Davis. University of California Davis developed a simulation that allows medical students to experience the effects of schizophrenia on perception. Additionally, students participated in simulated role plays with their cohorts and their professors, where they utilize and demonstrate necessary counseling skills. In an initial basic skills course or along with a counseling practicum, a virtual clinic/facility could be created and established in SL (i.e. like The Counseling Center in SL: slcounseling.org). Doctoral or advanced level (skilled) students could act as clients, while the entry level students could represent the (practicing) counselors. Faculty supervisors could provide setting variance by alternating between residential clinical settings, outpatient community settings, university counseling centers, etc. Simulation would mirror an actual environment where the student might later provide services. Faculty supervisors and instructors could review 
and monitor sessions and provide supervision and feedback.

The use of SL in this capacity could enhance experiential learning, allowing students to practice skills, try new ideas and learn from mistakes (Skiba, 2007). The opportunity to simulate counseling interactions allows for student skills demonstration, evaluation and remediation of practice before the student has to apply the skills in a real environment; such as in a practicum or in an internship. Students with various cultural backgrounds would have opportunities to explore cultural issues. The more opportunity the student has to reinforce knowledge of skills, and enhance their skills in counseling, the greater the likelihood that the student will enter the practicum environment with more confidence and competence. This could also translate to fewer student mistakes made over time in future real life practice. Students would have increased experiences to make mistakes in a less harmful environment; as well as more experiences with corrective evaluation in supervision. These experiences would also provide counselor educators opportunities in class to teach students about internet, online or web counseling (e.g., client interaction, treatment, ethical considerations, and practice implications) (Gregg \& Tarrier, 2007; Manhal-Baugus, 2001; National Board of Certified Counselors, 1997). Educating students about virtual counseling ethics and the potential benefits and hazards related to counseling in a virtual world would benefit students learning. Some instruction on these issues could also take place in SL.

\section{Collaboration and Consultation}

Student experiences with project based assignments within SL supports demonstration of learning; similar to that which is involved in developing the counselor education program portfolio. Student experience with this learning involves developing collaborative and consultative skills in completing programs of study and research. Based on a scholar/practitioner model of education, counselor education students are expected to engage in collaboration as they matriculate through programs of study. This collaboration does not have to be limited to the physical campus where the student is enrolled. SL could provide a venue for collaboration with students across counties and throughout the world. This would provide a mechanism to engage students in cooperative activities with other students. Additionally, co-teaching/presenting on special topic areas could provide collaboration skill development opportunities for students. This could be accomplished by hosting a virtual counseling in-service, meeting, lecture series or conference, as well as conducting some aspects of research in SL.

Virtual worlds offer tremendous opportunities for experimentation and research. SL could be considered particularly useful for doctoral students who conduct higher education research (Skiba, 2007). Because there is a paucity of literature on SL as a useful tool for research in general and collaborative research in particular, possibilities for future research are currently unlimited (Manghani, 2007). Research studies have not yet explored a comparison of the effects on learning in a traditional classroom environments and the SL environment. A paucity of research exists on the effects of the learning environment on communication and student engagement in counselor education. The compari- 
son of retention rates for traditional learning environment as opposed to ones that uses immersion learning strategies in a virtual world (such as SL) have also not been studied fully. In addition, future research in the area of SL has the potential to inform how we preparing future counselor educators to teach via distance or using web-based applications (Lebel, Olshtain, \& Weiss, 2005).

\section{Discussion}

Virtual worlds and proliferating online communities are projected to grow exponentially (Jarmon, Traphagan, \& Mayrath, 2008). Futurists even anticipate that programs similar to that of SL will become the preferred platform for cooperative learning (Childress \& Braswell, 2006). Students are becoming increasingly more technologically savvy and respond well to technology enhanced learning (Diehl \& Prins, 2008; Graham, 2007; Jarmon, Traphagan, \& Mayrath, 2008). Demands for distance education and more flexible class schedule options increases as student diversity continues to increase. Developing remote access to education benefits institutions of higher education and faculty, not only students. Boulos, Hetherington, and Wheeler (2007) propone educators are interested in widening access to education for geographically remote students and non-traditional learners. It goes without saying that there are obvious and necessary considerations in forging into these uncharted technological territories. Goral (2008) warned that schools could be taking on enormous risks for liability because SL is largely an "anything goes" world. Utilizing restrictions and limitations within SL will be critical to intercepting potential legal and policy issues. Despite these concerns, SL has gained popularity as a virtual world for learning. SL is currently being used by over 250 institutions of higher learning for various purposes. Many of these respected institutions are exploring the potential uses of this new virtual territory. SL has demonstrated potential for facilitating learning for students with a diversity of learning styles like kinesthetic learners who commonly struggle with traditional modes of education.

Proactively understanding the potential SL has for enhancing pedagogy and learning is a worthy endeavor for counselor education. As an instructional technology tool, SL could offer future counseling students additional educational opportunities to develop counseling skills while learning in a counselor education setting. Students could have experiential learning opportunities without doing real harm to clients thus enabling students to explore and practice interventions that they may not otherwise try. Despite the promise that SL offers, "several campuses reported low faculty interest in learning a new technology" (Eaton, Guerra, Corliss, \& Jarmon, 2011). Navigating new technological systems, especially three-dimensional environments, oftentimes come with a steep learning curve and are not for the faint at heart. Dedicated faculty who are not easily dissuaded who can accommodate time into an often busy schedule is necessary. Thus, finding time, money and technical support is necessary to entertain the possibilities of using SL with students. Yet, another challenge is peaking the interest of student motivation. Eaton et al. (2011) suggest that presenting students with the reasons for the technology use is key to motivation and seeing the relevance of its use when the learning curve for use is high.

Counselor Educators facilitate learning opportunities for counselors-in- 
training. Through simulated counseling practice, counselor educators can further assist in the development of student counseling competency. Competency development can include working with clients whose problems are related to virtual world use. Because some counseling is being conducted in SL, we know that the challenges include counseling clients with a) internet addictions, b) disrupted marriages because of internet use, c) virtual trauma or exposure, d) cyber bullying, and e) introversion or isolation (Dell, 2007; Young, 2007; Young, Griffin-Shelley, Cooper, O'Mara, \& Buchanan, 2000). As people increasingly engage with virtual worlds they may experience a break from reality and identify more with the virtual world than they do with real world interactions (Dell, 2007). This could potentially complicate diagnosis of some disorders that identify delusions or hallucinations (Yellowlees \& Cook, 2006).

The opposite side of assisting in the development of student counseling competency is the evaluation of that competency. Traditional classroom learning activities are usually faculty-developed. Virtual world learning activities are typically student-developed which gives freedom to demonstrate competency in the learning objective in as unique a way as the learner (de Freitas, RebolledoMendez, Liarokapis, Magoulas, \& Poulovassilis, 2010). Counselor training programs and faculty must evaluate the efficacy of virtual-based learning against that of traditional classroom learning (Freitas, et al., 2010). Two issues arise based on this information. One, this may require using a comparable set of evaluative measures to accommodate the differences in traditional and virtual learning. Second, the authors further note that where traditional classrooms may utilize Constructivist models of learning (i.e., "building upon existing knowledge"), a model of learning for virtual worlds may best utilize Situative approaches (i.e., a more social approach) (p. 73). The utilization of different approaches necessitates different forms of evaluation. This means the determination of student competency of a course's objectives may look different depending on the medium of learning activity. As well, this means that counselor educators may need to learn and adopt alternate teaching approaches to best facilitate learning specific and unique to virtual environments. For online counselor training programs that shift may not be as daunting. Nevertheless, for traditional classroom programs, it may seem insurmountable in light of the other faculty concerns aforementioned. This is critical in that if one is to design effective pedagogical interventions with new instructional technology thorough and detailed instructional planning must be implemented (Mayrath et al., 2011).

\section{Conclusion}

We have drawn from existing professional literature to offer suggestions that emphasized three areas of usefulness of SL for counselor preparation, training and education (i.e. programming, learning and skill development, and collaboration and consultation). These suggestions include the use of SL 1) as a marketing tool to recruit potential counseling students over greater distances; 2 ) to create more opportunities to develop counseling skills and educate students about potential benefits and hazards related to counseling in a virtual world; and 3) to facilitate collaborative and consultative learning activities with other students. 
Counselor educators need to know the students they teach in order to teach them more effectively. Technology is very much a part of who the next generation counselors are and will be. Being inclusive and responsive to future students includes examining the usefulness of virtual worlds (i.e. SL) for enhancing the preparation, training and education of the future counseling workforce. We need to be aware of the risks associated with this new territory.But there is no less of a need to enter it, be a part of defining how to use it safely and fairly; to effectively teach our students and help them serve our amazingly diverse clientele.

\section{References}

Athavaley, A. (2007, June 20). A job interview you don't have to show up for: Microsoft, Verizon others use virtual worlds to recruit; Dressing avatars for success. The Wall Street Journal. Retrieved from http:// online.wsj.com/article/SB118229876637841321.html

Bell, L., Pope, K., \& Peters, T. (2008). The universal library in a virtual universe. Searcher, 16, 26-61.

Berger, M. (2008). Manon of SL. Technology and Culture, 49, 430-441.

Bessiere, K., Fleming, A., Seay, A., \& Kiesler, S. (2007). The ideal elf: Identity exploration in world of warcraft. Cyber Psychology and Behavior, 10, 530-535.

Boulos, M., Hetherington, L., \& Wheeler, S. (2007). SL: An overview of the potential of 3-D virtual worlds in medical and health education. Health Information and Libraries Journal, 24, 233-245.

Bugeja, M. (2008). SL, revisited. Education Digest, 73, 23-27.

Cheal, C. (2007). SL: Hype or hyperlearning? Future Survey, 29, 18.

Childress, M. \& Braswell, R. (2006). Using massively multiplayer online roleplaying games for online learning. Distance Education ,27, 187-196.

de Freitas, S., Rebolledo-Mendez, G., Liarokapis, F., Magoulas, G., \& Poulovassilis, A. (2010). Learning as immersive experiences: Using the fourdimensional framework for designing and evaluating immersive experiences in virtual world. British Journal of Educational Technology, 41, 69-85. doi:10.1111/j.1467-8535.2009.01024.x

Dell, K. (2007, August 20). SL's real-world problems. Time, 170, 49-50.

Descy, D. E. (2008). Web browsers take another step forward. TechTrends: Linking Research and Practice to Improve Learning, 52, 6-7. 
Diehl, W. C. \& Prins, E. (2008). Unintended outcomes in SL: Intercultural literacy and cultural identity in a virtual world. Language and Intercultural Communication, 8, 101-118.

Eaton, L. J., Guerra, M., Corliss, S. \& Jarmon, L. (2011). A statewide university system (16 campuses) creates collaborative learning communities in Second Life. Educational Media International, 48(1), 43-53.

Foster, A. (2007, December 21). Immersive education submerges students in online worlds made for learning. Chronicle of Higher Education, 54 (17). ERIC Document Reproduction Service No. EJ783425.

Foster, A. (2007, December 7). Campuses in SL are second-rate, author says. Chronicle of Higher Education, 54(15), A26-A26.

Gaimster, J. (2007). Reflections on interactions in virtual worlds and their implication for learning art and design. Art, Design and Communication in Higher Education, 6, 187-199.

Geck, C. (2008, February 15). The making of SL: Notes from the new world. Library Journal, 133(3), 114-115.

Goral, T. (2008). Sizing up SL: Higher ed learns how to live in a virtual world. University Business, 11, 60-64.

Graham, S. (2007). Second lives: online worlds for archaeological teaching and research. European Journal of Archaeology, 10, 77-79.

Gregg, L. \& Tarrier, N. (2007). Virtual reality in mental health: A review of the literature [Electronic version]. Social Psychiatry and Psychiatric Epidemiology, 42, 343-354.

Guest, T. (2007). Second lives: A journey through virtual worlds. London: Hutchinson.

Harasim, L. (2000). Shift happens: Online education as a new paradigm in learning. Internet and Higher Education, 3, 41-61.

Jarmon, L., Traphagan, T., \& Mayrath, M. (2008). Understanding project-based learning in SL with a pedagogy, training, and assessment trio. Educational Media International, 45, 157-176.

Jencius, M. (2009). Training and counseling in a virtual world. Counseling Today, 28-29.

Kelton, A. (2008). Virtual worlds. Educause Review, 43(5), 15-22. 
Korolov, M. (2010, September 11). What to wear to a virtual job interview. Hypergrid Business, Retrieved from http://

www.hypergridbusiness.com/2010/09/what-to-wear-to-a-virtual-jobinterview/

Lebel, T., Olshtain, E., \& Weiss, P. L. (2005). Teaching teachers about augmentative and alternative communication: Opportunities and challenges of a web-based course. Augmentative and Alternative Communication, $21,264-277$.

Liao, C. (2008). Avatars, SL, and new media art: The challenge for contemporary art education. Art Education, 61(2), 87-91.

Manghani, S. (2007). MyResearch.com: speculations on bridging research and teaching in the arts. Art, Design and Communication in Higher Education, 6(2), 85-98. doi:10.1386/adch.6.2.85_1

Manhal-Baugus, M. (2001). E-therapy: Practical, ethical, and legal issues. Cyber Psychology and Behavior, 4, 551-563.

Mayrath, M. C., Traphagan, T. T., heikes, E.J., \& Trivedi, A.A. (2011). Instructional design best practices for Second Life: a case study from a college -level English course. Interactie Learing Environments, 19(2), 125-142. 494820802602568

Markham, A.N. (1998). Life online. Walnut Creek: Alta Mira Press.

National Board of Certified Counselors (1997). The practice of internet counseling. Greensboro, NC: Author.

Olsen, F. (2000). Scholars in medicine and psychology explore uses of virtual reality. Chronicle of Higher Education, 47, A46-A46.

Patrick, P. K. S. (2007). Contemporary issues in counseling. Boston, MA: Pearson.

Petrakou, A. (2010). Interacting through avatars: Virtual worlds as a context for online education. Computers \& Education, 54, (4) 1020-1027.

Reicherzer, S., Dixon-Saxon, S., \& Trippany, R. (2009). Quality counselor training in a distance environment. Counseling Today, 46-47.

Robbins-Bell, S. (2008). Higher Education as: Virtual conversation. Educause Review, 43(5), 24-34.

Skiba, D. (2007). Nursing education 2.0: SL. Nursing Education Perspectives, 28, 156-157. 
Trotter, A. (2008). Educators get a 'SL'. Education Week, 27, 1-17.

Yee, N., Bailenson, J.N., Urbanek, M., Chang, F., \& Merget, D. (2007). The unbearable likeness of being digital: The persistence of nonverbal social norms in online virtual environments. Cyber Psychology and Behavior, 10, 115-121.

Yellowlees, P., \& Cook, J. (2006). Education about hallucinations using an internet virtual reality system: A qualitative survey. Academic Psychiatry, 30, 534-539. doi:10.1176/appi.ap.30.6.534

Young, K. (2007). Cognitive behavior therapy with internet addicts: Treatment outcomes and implications. Cyber Psychology and Behavior, 10, 671679.

Young, K.S., Griffin-Shelley, E., Cooper, A., O'Mara, J., \& Buchanan, J. (2000). Online infidelity: A new dimension in couple relationships with implications for evaluation and treatment. Sexual Addiction and Compulsivity, 7, 59-74. 